\title{
JOHN LENNON: O LÍDER E O PRODUTO
}

\author{
Guilherme Lentz da Silveira Monteiro*
}

RESUMO :

John Lennon é um representante fundamental da cultura juvenil no pós-guerra. Em suas vârias fases, sua obra procura desestabilizar categorias sociais cristalizadas, propondo uma postura rebelde, em um processo dessacralizador. Sua morte, porém, indica que as propostas otimistas de sua geração não foram assimiladas.

PALAVRAS-CHAVE: juventude, rebeldia, Lennon, beatlemania.

A memória de John Lennon reaparece sempre cercada de uma espécie de saudosismo. "0 sonho não acabou", repete-se na imprensa. Ao lado dessa declaração, porém, comumente se lembra também a frase original de Lennon, declamada pela primeira vez na canção "God", do álbum John Lennon/ Plastic Ono Band (1970): "o sonho acabou". Uma análise da forma como a morte de Lennon foi recebida por seus contemporâneos pode ser o primeiro passo para que se compreenda essa postura ambígua. Nas muitas canções ou textos publicados em jornais e revistas que se seguiram à morte do artista fica evidente a sensação de que uma era chegava ao fim. Para as pessoas que cresceram durante as décadas de 50, 60 e 70, o ex-beatle tinha uma força simbólica. Trata-se de uma geração que se caracterizou pela busca por alternativas de organização social, por uma tentativa otimista de se negar o mundo que haviam herdado de seus pais. A morte de Lennon é apreendida como o marco final desse projeto, cuja falência, de resto, ele mesmo já pressentira em 1970.

Sua obra coincide, assim, com o momento em que a juventude ganha força como uma entidade social, e, possivelmente pela primeira vez, há a proposta de se criar uma cultura jovem. Lennon nasce em 1940, enquanto Liverpool, sua cidade natal e até então uma espécie de mostruário de valores cultuados durante séculos na

* Mestre em Letras: Estudos Literários (Área de concentração: Teoria da Literatura), 2001. 


\section{EM TESE}

Belo Horizonte, v. 6, p. I-253, ago. 2003

sociedade ocidental, era impiedosamente devastada por bombardeios nazistas. Desses valores em ruínas tenta emergir uma nova mentalidade, que questiona o velho mundo e propõe alternativas. A obra de John Lennon, que em muitos pontos se confunde com sua vida, surge nesse cenário e se desenvolve durante as décadas de 50, 60 e 70 período que pode ser considerado a era do rock -, coincidindo com o percurso de sua geração rebelde desde a adolescência até a vida adulta e, nesse processo, refletindo os anseios e as decepções que marcaram os filhos da guerra.

Em um primeiro momento, John Lennon dedica-se a uma produção marcada por um otimismo hesitante e uma progressiva consciência do papel da mídia, essa outra grande entidade cujo desenvolvimento também coincide com a era do rock. Ao mesmo tempo causa e efeito desse fenômeno, Lennon às vezes mostra-se eufórico, celebrante; outras vezes, como em "I'm a loser", dá sinais da presença de uma insatisfação que mais tarde terá efeitos. De modo geral, entretanto, pode-se dizer que a poesia dos primeiros anos de carreira de John Lennon, que se confundem com o período áureo dos Beatles, é caracterizada por uma fé na nova condição da juventude, nas recémadquiridas liberdades, na legitimidade da própria figura do popstar. Os Beatles surgem como messias de um novo tempo e a princípio esse papel é aceito.

Bastante representativa dessa primeira fase é a canção "The Word", do álbum Rubber soul, de 1965. O termo word é normalmente traduzido para o português como "palavra". Entretanto, nesse caso "verbo" seria a tradução mais adequada, de modo a tornar mais clara a referência ao evangelho de João, cujo texto em inglês se inicia com "In the beginning there was the word". É desse verbo que John Lennon fala; desse verbo bíblico, que é luz resplandecente nas trevas e incompreendido pelos homens. Essa filiação de "The word" ao texto bíblico é possível graças a uma série de referências à tradição cristã. Reafirmando a incompreensão humana frente ao verbo, por exemplo, Lennon canta, retomando João quase textualmente: "In the beginning I misunderstood / but now I got it, the word is good". Em outro momento, há os versos "Now that I know what I felt must be right / I meant to show everybody the light", em que a luz, antiga metáfora de um Deus todo-poderoso e do amor que Ele encerra, é retomada, ao mesmo tempo em que há um comprometimento com a divulgação dessa boa nova. Nos versos "Say the word and be like me/ say the word and you'll be free" e "Spread the word and you'11 be free/ spread the word and be like me" há uma 
clara postura messiânica: Lennon evoca Jesus Cristo, que em mais de uma ocasião ordena a seus discípulos que sigam seu exemplo e vivam como ele.

Ao lado dessa postura messiânica, "The word" traz um elemento que se tornaria comum na obra de John Lennon nos anos 70: a linguagem da propaganda. Percebendo-se inescapavelmente parte de um mercado, o artista tenta se apropriar dessa situação, dominando as estratégias de propaganda para inserir um ruído dentro do universo de consumo. Em "The word" essa tentativa é percebida, por exemplo, no exaustivo uso de verbos no imperativo e na exaltação das características mágicas desse verbo-produto, como em "It's so fine, it's sunshine". A súbita intervenção de voz em primeira pessoa, em um verso cantado individualmente por Lennon, contrapõese ao tom impessoal das demais estrofes, cantadas por um coro, em uma estrutura semelhante à de um comercial em que uma voz sem rosto, que visa a representar a instituição anunciante, é intercalada com depoimentos de consumidores.

Em "A11 you need is love", de 1967, Lennon retoma, de forma já mais incisiva, a preocupação com a linguagem da propaganda e a manipulação das mídias. 0 texto da canção, gravada para a primeira transmissão via satélite da história, é composto por uma série de aforismos, como "There's nothing you can do that can't be done", "There's nowhere you can be that isn't where you're meant to be" e o próprio título. 0 que insere "A11 you need is love" em uma proposta de rebeldia, entretanto, é a referência crítica à Marselhesa. 0 hino francês, como se sabe, conta com um texto de orientação nacionalista, em que se convocam as crianças da pátria a tomarem as armas e marcharem para lutar. Tal texto sustenta as propostas de "liberdade, igualdade e fraternidade" que moldam o discurso burguês desde o final do século XVIII, legitimador do sentimento nacionalista e do individualismo. Lennon, por sua vez, retoma a Marselhesa para introduzir uma canção de circulação internacional e de cunho pacifista, em que se defende a grandeza do homem em sua própria humanidade. Os falidos ideais burgueses de "liberdade, igualdade, fraternidade" dão lugar a "love, love, love"; o chamado à guerra cede espaço para a declaração da urgência do amor. Um hino pretende construir e definir uma identidade nacional, mas Lennon tenta exatamente o oposto: valer-se de uma nova tecnologia de comunicação para desconstruir essa visão de mundo baseada no nacionalismo e no indivíduo. 


\section{EM TESE}

Belo Horizonte, v. 6, p. I-253, ago. 2003

Há um elemento complicador na proposta de Lennon de utilizar a grande mídia como um instrumento de transformação social. Sem os meios de comunicação eles mesmos instrumentos de manutenção da ideologia dominante que o cantor pretende combater, há uma tendência de que a própria rebeldia seja assimilada pelo sistema, esvaziando-se seu poder transformador. A transmissão via satélite de "All you need is love" confere aos Beatles um grande poder, mas é também sinal de uma institucionalização do grupo, cujos integrantes, nessa época, já haviam sido condecorados como membros do Império Britânico; cuja obra, nessa época, já fora considerada pelo governo como o "melhor produtor de exportação" da Inglaterra. Lennon percebe-se aprisionado nessa armadilha e sabe que a manutenção de sua poética rebelde depende da construção de novas estratégias culturais. Inicia-se com essa percepção uma nova fase na obra do artista, uma fase em que se negam os dogmas que haviam orientado sua atuação no passado.

Percebe-se que a imagem do popstar, sacralizada na grande mídia, é um grande alvo de John Lennon. Há por parte do artista uma tentativa em se despir de sua imagem de ídolo, buscando uma figura mais humana, mais real. Uma das principais estratégias nessa nova proposta é uma nova orientação na forma como o artista trabalha sua biografia, que a partir desse momento passa a se confundir com sua obra, a tal ponto que muitas vezes é impossível ou fora de propósito entendê-las separadamente. Lennon realiza o que pode ser considerado como uma ficcionalização de sua biografia. Texto, música, família, acontecimentos, reflexões pessoais, todos esses elementos passam a ser trabalhados por Lennon como parte de um corpo artístico, que é, ao mesmo tempo, o próprio corpo do artista.

É bastante representativo dessa nova proposta o álbum Two virgins, que marca também o início da parceria/casamento com Yoko Ono, ela mesma uma grande artista. Na famosa capa do álbum, gravado na primeira noite de amor de Lennon e Yoko, o casal aparece nu, em uma nítida alusão a Adão e Eva, o casal que preferiu comer o fruto proibido e ser expulso do Paraíso a viver em um mundo sem amor. Nu, John Lennon está abandonando sua roupagem de ídolo; compartilhando o amor proibido com Yoko Ono, está se condenando também a uma existência fora do Paraíso, mas a uma existência real. A esse despojamento simbólico corresponderá uma nudez musical e poética, já que os textos, melodias e arranjos nas canções de Lennon se tornarão 
mais contidos, em oposição à exuberância psicodélica que caracterizara sua obra nos anos anteriores. Finalmente, era apenas natural que acontecesse um passo indispensável a esse processo de dessacralização: a dissolução dos Beatles.

A canção "God", lançada em 1970, justamente quando se anunciava o fim do grupo, é a que melhor traduz essa fuga do paraíso beatlemaníaco. Em "God" Lennon realiza uma verdadeira antigenealogia de si mesmo, negando todos os ídolos que compõem sua tradição cultural, desde os antigos magos a Elvis Presley, passando por Jesus, Kennedy, os reis e, finalmente, os Beatles. A canção tem a grandiloqüência característica do produtor, o lendário Phil Spector, responsável pela criação da "wall of sound", uma estética pop que marcou vários clássicos dos anos 50 e que consiste, entre outros fatores, na multiplicação de vozes e instrumentos de modo a se conseguir um efeito avassalador. Lennon aproveita-se magistralmente da técnica de Spector, permitindo, durante toda a primeira parte da canção, que predomine um tom grandiloqüente. Com isso, "God" evolui em um tenso crescendo, que explode, como se a própria muralha sobre a qual é construída tombasse, em uma retumbante declaração: "I don't believe in Beatles". Após um breve silêncio, ressurge do alto-falante uma nova voz, humana, nua, despida da produção de Spector, com a qual Lennon afirma sua não-divindade: "I just believe in me/ Yoko and me/ and that's reality". "The dream is over", conclui Lennon, referindo-se aos Beatles, a seu tempo, à crença ingênua de que sua geração cumpriria naturalmente sua messiânica missão transformadora.

Os gestos de Lennon ao se negar como Beatle, como walrus, como tecedor de sonhos, indicam uma tentativa em se fazer uma arte com conteúdo rebelde constantemente reinventado. John Lennon parece perceber que, produzindo em universo que tende a assimilar e esvaziar toda novidade, a modificação constante é o preço da rebeldia. Por isso, metamorfoseia-se continuamente, tonando-se um artista de difícil enquadramento. Órfão, vítima, rebelde sem causa, rebelde com causa, pacifista, psicodélico, apaixonado, machista, feminista, popstar, underground, ativista, ator, produtor, poeta: quem, afinal, é John Lennon? Ele foge a qualquer tentativa de se responder a essa questão, construindo-se como um nômade, um viajante indefinível, impossível de ser apreendido em fronteiras, nos limites preestabelecidos na cultura. Sua atuação obriga o público a um constante interrogar sobre a verdadeira mas sempre escorregadia natureza de seu trabalho, e, nesse processo, o público termina por interrogar-se a respeito de sua própria inserção no mercado, na cultura, no mundo. 


\section{EM TESE}

Belo Horizonte, v. 6, p. I-253, ago. 2003

Mesmo a proposta de uma renovação constante, porém, pode ser desvendada, e, ciente disso, John Lennon tenta escapar dessa armadilha, atirando uma última carta em 1975, quando tenta uma ruptura final e decide exilar-se em seu apartamento no edifício Dakota, em Nova Iorque, alegando que pretende cuidar da casa e de seu novo filho, Sean, o único com Yoko. Durante os cinco anos seguintes, Lennon se impôs um silêncio criativo, só aparecendo em público para raros eventos e viagens com a familia. Sabe-se hoje que essa quietude foi ela mesma um ato artístico. Graças primeiramente a lançamentos clandestinos e posteriormente à divulgação, feita por Yoko Ono, o público sabe que durante seus cinco anos de suposto silêncio, John Lennon compôs muitas canções inéditas, escreveu, filmou e, claro, adicionou mais um personagem a sua galeria de máscaras: o de pai dedicado e marido exemplar, o que, segundo alguns biógrafos, é muito diferente da realidade.

Entretanto, quando o artista inesperadamente voltou a ser visto em estúdios em meados de 1980, contando a história de uma miraculosa inspiração, o púbico celebrou o retorno do ídolo como se celebra a ressurreição de um líder. John Lennon e Yoko Ono voltavam felizes, festejando o amor, sua união, o amadurecimento. Lennon chegava mesmo a dar um passo atrás, reassumindo - ainda que inadvertidamente - seu papel como líder em sua geração. Em suas últimas entrevistas, repetia que seu objetivo naquele momento era transmitir para as pessoas seu modo de relacionamento, as 1 ições da vida adulta, para que, como ele fizera, outros pudessem fazer também. Como em "The word", anos atrás, percebe-se nessa postura uma quase-citação ao discurso de Cristo a seus apóstolos em seu encontro final: ele veio para dar o exemplo, para que outros aprendessem a lição.

Lennon, entretanto, teve uma surpresa negativa ao abandonar seu esconderijo e renovar seu contato com a cultura de massa. 0 que ele encontrou foi um mundo bem diferente do que se poderia esperar dos jovens idealistas que haviam levantado a voz nas décadas anteriores. Tantos desejos rebeldes aparentemente não resistiram à vida adulta, e embora liberdades tivessem sido conquistadas, não se atribuía o devido valor a elas. Assim, a última mensagem de John Lennon oscila entre o otimismo e a decepção. Por um lado, há a celebração da liberdade, mas a percepção de uma vulgarização incomoda. Em "Nobody told me", canção do álbum Milk and honey, em que o artista trabalhava no final de 1980 , Lennon discute esse paradoxo, em versos como 
"Everyobody's talking/ and no one says a word", "everybody's making love/ and no one really cares". Em versos como "There's always something happening/ and nothing going on", explicita-se a contradição inerente a uma geração em que tudo perdeu 0 valor exatamente no momento em que tudo se tornou permitido.

Milk and honey, o título do álbum em que Lennon pretendia incluir "Nobody told me", é uma referência ao momento do Gênesis em que Deus se manifesta a Moisés no deserto e promete ajudá-10 a liderar o povo judeu rumo à liberdade, rumo à terra encantada de Canaã. Como se sabe, Moisés guia os judeus através do deserto durante quarenta anos, mas, por ter duvidado de Deus, é punido e morre avistando a terra prometida, sem conseguir alcançá-la. Seu corpo foi sepultado em um local desconhecido, restando-1he, entretanto, a recompensa de nunca ter sido superado por nenhum outro profeta e de ter sido o único dentre todos com quem Deus tratou face a face. A seu modo, John Lennon também liderou seu povo a uma terra de prosperidade e liberdade e certamente teve consciência disso, pois, em "I don't wanna face it", outra canção de Milk and honey, afirmou: "Well I can see the promised land/ and I know I can make it", acreditando poder corromper a analogia com o líder judeu e desfrutar do que conquistara. Aparentemente, a percepção melancólica de que aqueles eram dias estranhos, de fato, não era suficiente para impedir que Lennon tentasse mais uma vez, vestisse sua nova fantasia de nova-iorquino cosmopolita e saísse às ruas em busca de novas experiências.

Infelizmente, esse otimismo também não foi suficiente para diminuir a verdade do que Lennon captara em "Nobody told me", e não é novidade que, no dia 8 de dezembro de 1980, ele foi traído por um seguidor e assassinado com cinco secos tiros, em frente ao Dakota, quando voltava de uma sessão de gravações.

Nunca houve uma morte como a de John Lennon. 0 mundo já o perdera muitas vezes. Primeiramente quando se tornou pública a notícia de que era casado; depois quando os Beatles interromperam as excursões, em 1966; mais tarde aconteceu a união com Yoko Ono; em 1970 separaram-se os Beatles; em 1975 o cantor se afastou do público. Tudo isso atingira em maior ou menor escala os fãs dos Beatles, mas a noite de 8 de dezembro foi devastadora para muitos mais. Lennon carregava uma aura da 


\section{EM TESE}

Belo Horizonte, v. 6, p. I-253, ago. 2003

década de 60 , de uma era em que as pessoas acreditaram em uma transformação positiva do mundo. Sua morte coincide com um momento em que tal crença se desfazia e em que sua geração se confrontava duramente com seus fracassos, sua fragilidade ideológica e suas próprias incoerências. Nesse sentido, a morte de John Lennon é tão significativa, é tão simbólica, que poderia ser tomada como uma encenação, como o ponto final, trágico e coerente, de uma obra que teve a biografia do próprio artista como matéria-prima.

Para alguns estudiosos, enquanto os jovens roqueiros, hippies e ativistas buscavam revolucionar o mundo na era do rock, uma revolução perversa e muito mais profunda consolidava-se silenciosamente, levada a cabo não por aqueles que se vestiam de forma diferente, tampouco por aqueles que tocavam guitarras, mas pelas pessoas comuns, que se mantiveram à margem dos movimentos juvenis do pós-guerra. Essas pessoas consolidaram a gestação, iniciada com a modernidade, de uma sociedade individualista e distante de ideais afetivos e solidários. Assim, pode-se dizer que a cultura do rock'n'roll é, em certo sentido, conservadora, pois pretendeu exatamente impedir essa transformação, mas não obteve sucesso.

A vitória que resta a John Lennon é paradoxalmente a vitória amarga que resta a um messias. Seu projeto artístico falhou em vários de seus pontos principais. Ele conseguiu se transformar constantemente, mas isso não foi suficiente para impedir sua institucionalização. Com "Imagine" sendo eleita a canção do século na Europa que assiste ao renascimento do fascismo, com a mesma canção sendo trilha sonora de programas de televisão em um país onde crianças desarmadas são corriqueiramente assassinadas por policiais, com tantas contradições, restam poucas dúvidas de que parte importante da mensagem se vulgarizou, foi reembalada para 0 consumo fácil dos alienados. A tentativa de escapar de um messianismo também não foi bem sucedida, pois, quanto mais John Lennon reafirmou sua humanidade, mais sagrado se tornou aos olhos daqueles que o acompanhavam. Por outro lado, novas tecnologias vêm e vão, artistas surgem e desaparecem, e os aparelhos permanecem ligados, e, ao redor deles, como ao redor de um altar, as pessoas continuam cantando a obra de Lennon, e por causa dele novas amizades se formam, e novos sonhos se tecem. No final, como na trajetória de todo grande líder, como na trajetória daquilo que John Lennon evitou insistentemente se tornar, o que restou de fato foi uma semente. E o 
que é pior, para uns, ou melhor, para outros, é que seus fãs - os mais fiéis - o amam justamente por isso.

ABSTRACT :

John Lennon is a major name in post-war youth culture. In various moments, his work tries to break crystallized social categories, suggesting a rebellious approach to society. His death, however, indicated that the optimistic views of his generation have not been assimilated.

KEY WORDS: youth, rebellion, Lennon, beatlemania.

BENNET, Andy. Sitting in an English garden: comparing representations of britishness in the songs of the Beatles and 1990s britpop groups. In: INGLIS, Ian (org.). The Beatles, popular music and society; a thousand voices. New York: Saint Martin, 2000.

BÍBLIA SAgRAdA. 2. ed. São Paulo: Sociedade Bíblica do Brasi1, 1993.

GROPPO, Luís Antônio. Juventude. Rio de Janeiro: Difel, 2000 .

MACDONALD, Ian. Revolution in the head; the Beatles' records and the sixties. New York: Henry Holt, 1994. 